\title{
Foot rot due to Corynebacterium pyogenes infection in a cow: A Case Report
}

\author{
*Faez Firdaus Jesse Abdullah ${ }^{1,3}$, Konto Mohammed ${ }^{1,4}$,Lawan Adamu ${ }^{1,4}$, Yusuf \\ $\mathrm{Abba}^{2,4}$, Abdinasir Yusuf Osman ${ }^{1,2}$, Abdulnasir Tijjani, ${ }^{2,4}$, Abdul Aziz Saharee \\ 1,3 and Abdul Wahid Haron ${ }^{1,3}$ \\ ${ }^{I}$ Department of Veterinary Clinical Studies; ${ }^{2}$ Department of Veterinary Pathology and Microbiology; \\ ${ }^{3}$ Research Centre for Ruminant Disease, Faculty of Veterinary Medicine, Universiti Putra Malaysia, 43400 \\ UPM Serdang, Selangor, Malaysia; ${ }^{4}$ Faculty of Veterinary Medicine, University of Maiduguri, PMB 1069,
}

Borno State, Nigeria.

\begin{abstract}
Foot rot is a painful condition resulting in moderate to severe lameness in cattle but with early intervention and vigorous treatment, most cases will have a favourable outcome. A 4 year old Kedah-Kelantan cow weighing 250kg was presented to the large animal unit of the University Veterinary Hospital, Universiti Putra Malaysia, with the complain of lameness for 5 days. Physical examination findings were pyrexia, inappetence and lameness. Blood analysis revealed neutrophilia with left shift, while the biochemical analysis revealed an increase in aspartate aminotransferase, creatine kinase and globulin levels. Bacterial culture from the swab samples of the cow's hoof revealed growth of Corynebacterium pyogenes. The hoof was disinfected with povidone iodine and Benacillin injection $(25 \mathrm{mg} / \mathrm{kg})$, Flunixine meglumine $(1.1 \mathrm{mg} / \mathrm{kg})$ and multivitamin $(10 \mathrm{mg} / \mathrm{kg})$ injections were administered intramuscularly. The hoof was washed with $5 \%$ copper sulphate solution once daily. The prognosis was good after a follow up visit one week later. Early intervention is paramount in addressing foot rot caused by bacterial organisms in cattle.
\end{abstract}

Keywords: Corynebacterium pyogenes; Foot rot; Lameness; Hoof

\section{Introduction}

Foot rot, also known as interdigital phlegmon or infectious pododermatitis is an infectious disease in cattle characterized by lameness and inflammation of soft tissues between the hooves or interdigital spaces (Dewell, 2009; Maas, 2009). It is a major cause of acute lameness in beef cattle. The condition may become chronic when left untreated or when treatment is delayed, thus allowing other structures of the foot to become involved (Greenough, 2007). The common causative agents of Foot rot are soil borne bacteria; Fusobacterium necrophorum and Bacteroides melaninogenicus, which gain entry via an injured skin into the interdigital space. However, other soil borne bacteria, including Staphylococcus aureus, Escherichia Coli, Corynebacterium pyogenes and Porphyromonas levii have been reported to cause this condition (Griffin, 1998; Greenough, 2007; Lincoln, 2009; Maas, 2009). The condition is seen all year round and the most common predisposing factor is injury to the foot skin, usually caused by trauma due to stepping on stones, straw or hardened mud, or continuously standing in a wet muddy environment, which may soften and macerate the skin (Currin et al, 2009; Lincoln, 2009). Occasionally, the condition may occur in the absence of an obvious inter-digital trauma (Stokka et al., 2001; Currin et al, 2009; Lincoln, 2009). Although all ages of animals are susceptible, the condition is most common in cattle of weaning age and older. Morbidity can vary from one or two animals in the herd to large outbreaks (Griffin, 1998; Currin et al., 2009).

Foot rot infection can cause great economic loss to the farmer by a reduction in milk production in dairy cattle and reduced mass in beef cattle (Kausche \& Robb, 2003). This report evaluates the clinical significance and management of foot rot in cattle due to Corynebacterium pyogenes.

History and signalment

\section{Case report}

A 4 year old Kedah-Kelantan cow weighing 250kg (Fig.1) was presented to the large animal unit of the University Veterinary Hospital Universiti Putra Malaysia with the complain of inappettence, reluctance to move and an abnormal gait which was noticed 5 days prior to presentation. The cow was kept under semi-intensive system and fed with commercial pellets and pasture. 


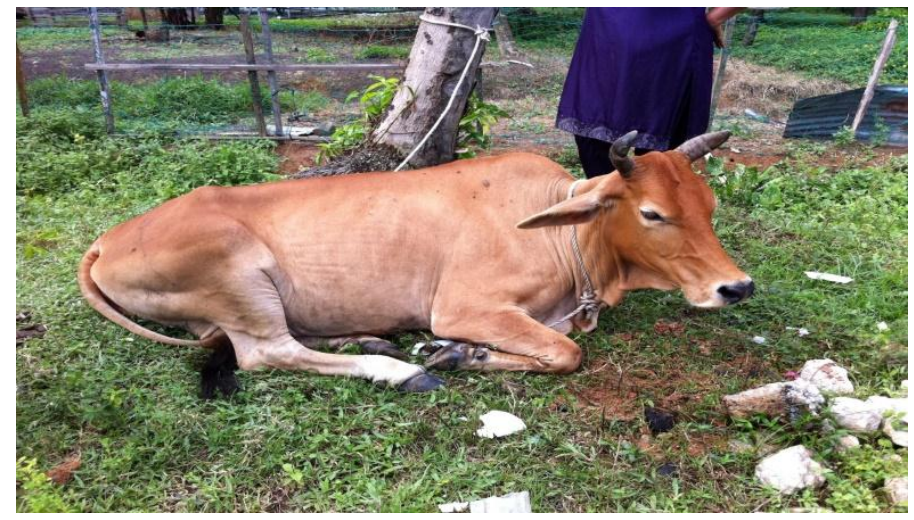

Fig. 1: showed lame cow in sternal recumbency.

\section{Physical examination}

On physical examination, there was pyrexia, reluctance to move and an abnormal gait. The interdigital tissues of the hooves were soft, swollen and reddened with foul smelling odour (Fig. 2).

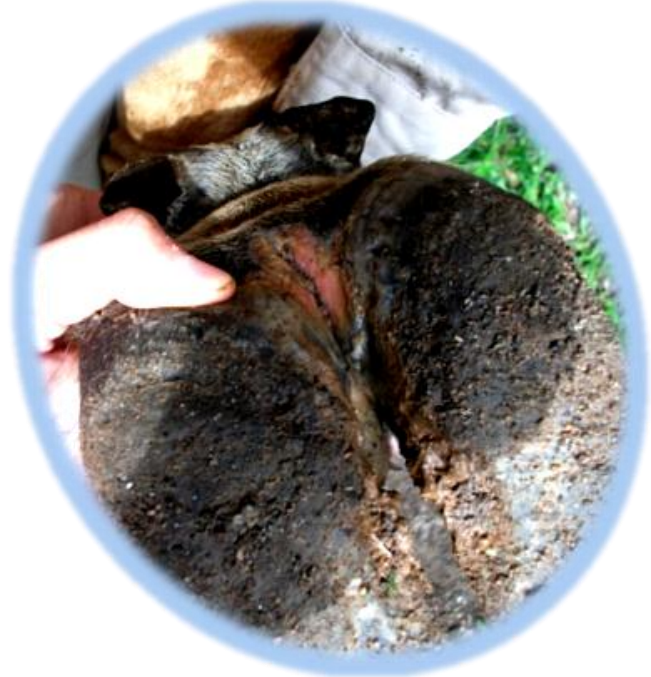

\section{Diagnostic plan}

Fig. 2: showed inflamed interdigital region of the forelimb

Blood sample was taken for complete blood count and biochemical analysis. Sterile swap sample was taken from the interdigital space and sent for bacterial culture and isolation. Complete blood count was determined by using (Cell DYN 3700, Abbot) and hematocrit (Hettich-Hematocrit 210 and Hawksley microhematocrit reader) was used for estimation of packed cell volume. Plasma electrolyte and biochemical parameters were determined with chemistry analyser (Hitachi 920) using standard diagnostic kits (Roche). For bacterial isolation, swabs were streaked onto blood agar, McConkey and XLD agar and incubated both aerobically and anaerobically for 24 hours to observe growth, colonial appearance. Gram staining and biochemical test such as indole, catalase, oxidase, $\mathrm{H}_{2} \mathrm{~S}$ and nitrate production were used to characterize the resultant colonies.

\section{Results}

The hemogram showed neutrophilia $\left(6.96 \times 10^{9} / \mathrm{L}\right)$ with left shift without a leucocytosis, while biochemical analysis showed an increase in aspartate aminotransferase $(108.1 \mathrm{U} / \mathrm{L})$, creatine kinase $(1756 \mathrm{U} / \mathrm{L})$ and globulin $(62.9 \mathrm{~g} / \mathrm{L})$. Bacterial culture showed a gram positive slender rod, which was translucent and had a haemolytic area on blood agar. The isolate was indole, $\mathrm{H}_{2} \mathrm{~S}$ and nitrate negative. This confirms that the resultant isolate is Corynebacterium pyogenes.

\section{Treatment}

The hooves were washed with hibiscrub and povidone iodine was applied topically. Benacillin $(25 \mathrm{mg} / \mathrm{kg}$ i.m), Flunixine meglumine (Norbrook laboratories, New Zealand; $1.1 \mathrm{mg} / \mathrm{kg}$ i.m x 3/7) and multivitamin injections (Norbrook laboratories, New Zealand; $10 \mathrm{mg} / \mathrm{kg}$ ) were administered intramuscularly. Hoof dressing was performed with 5\% copper sulphate solution once daily until the hooves hardened. The 
condition improved after a few days and the cow was able to walk with a normal gait after one week of treatment.

\section{Discussion}

Rapid response to antibiotic therapy is always seen in the cases of foot rot (Dewell, 2009; Maas, 2009). This finding was evident in the present case report. Topical treatment can be accomplished by thoroughly cleaning the foot and applying an astringent such as 5\% copper sulphate (Maas, 2009), while anti-inflammatory, analgesics and anti-pyretic drugs will help to reduce pain and prevent major bacterial complications that may arise. Bacterial infections are usually accompanied by changes in white blood cell population and increase in neutrophil counts is an indication of bacteremia (Jackson, 2013). We observed neutrophilia with left shift, which was a response to the bacterial infection. Hyperglobulinemia was also observed which may be attributed to the inflammatory condition as reported by (Seebach et al., 1997; Jackson, 2013), that there was an increase in globulin concentration in the blood following bacterial infections and inflammation. The slight rise in serum aspartate aminotransferase and creatine kinase is an indication of muscular dystrophy. Pavlata et al. (2001) reported an increase in AST and CK in cows that developed muscular dystrophy due to change in housing. The authors observed that both AST and CK increased signify an acute dystrophic condition of the muscle, while an increased AST with a stable CK level signifies remission of the condition.

Isolation of Corynebacterium pyogenes from the infected hooves confirms the association of the bacterium with the condition. Corynebacterium pyogenes is a pyogenic organism that has been incriminated in many septic conditions including mastitis in dairy cows. Although its association with foot rot have been previously reported (Greenough, 2007; Lincoln, 2009), there is paucity of information on its association with foot rot of cattle in Malaysia.

\section{Conclusion}

We reported the association of Corynebacterium pyogenes with foot rot in Cattle and the resultant haematological and biochemical disruptions associated with the condition. Prompt intervention with parenteral antibiotic administration and topical wound dressing showed tremendous success in the recovery of the condition as was observed after a week.

\section{Acknowledgement}

The authors wish to acknowledge En Nazim Razali Kanini, En Mohd Jefri and Mr. Velloo of University Veterinary Hospital (UVH), and Faculty of Veterinary Medicine Universiti Putra Malaysia for their technical assistance.

\section{Reference}

[1]. Arkins, S.(1981). Lamess in dairy cows. Iran Veterinary Journal. 35: 135-140.

[2]. Currin. J. F, Whittier. W.D \& Currin. N, (2009). Foot Rot in Beef Cattle. Communications and Marketing, College of Agriculture and Life Science, Virginia Polytechnique Institute and State University.

[3]. Dewell. G. and Shearer, J.K. (2009). Foot Rot In Beef Cattle. Cooperative Extension Service, Iowa State University of Science and Technology, Ames, Iowa.

[4]. Greenough, P.R. (2007). Bovine Laminitis and Lameness. Philadelphia, WB Saunders, pp. 199-205.

[5]. Griffin, D.D. (1998). Feedlot Diseases, Vet Clin North Am Food Anim Pract (14). Philadelphia, WB Saunders, pp. $213-215$.

[6]. Irshik, M. B.and Shearer. J.K.(2010). Foot Rot in Cattle. Veterinary Medicine-Large Animal Clinical Sciences Department, Florida Cooperative Extension Service, Institute of Food and Agricultural Sciences, University of Florida.

[7]. Jackson, M.L (2013): Veterinary Clinical Pathology: An introduction. John Wiley and Sons., 171-193.

[8]. Kausche. F. M. and Robb. E. J, 2003. A comprehensive review of ceftiofur sodium and hydrochloride formulations for treatment of acute bovine foot rot. Veterinary Therapeutics. 4 (1): 83-93.

[9]. Lincoln, S.D. (2009). Infectious foot rot of cattle. Beef cattle handbook, BCH-A3225. Product of extension beef cattle resource committee. Adapted from the cattle proders's library ACT of May 8 and June 30, 1914.

[10]. Maas, J. (2009). Treating and preventive foot rot in cattle. UCD Vet. Views. California cattle men's magazine July/August 2009.

[11]. Pavlata, L. Pechova, A and Illek, J (2001). Muscular dystrophy in dairy cows following a change in housing technology. Acta Vet. Brno., 70: 269-275.

[12]. Seebach, J.D., Morant, R., Ruegg, R., Seifert, B. and Fehr, J. (1997). The diagnostic value of the neutrophil left shift in predicting inflammatory and infectious diseases. Am. J. Clin. Pathol. 107(5): 582-91.

[13]. Stokka, G.L. Lechtenberg, K.F., Edwards, T., MacGregor, M., Griffen, D., Grotelueschen, D.M., Smith, R.A. and Perino, L.J. (2001). Lameness in feedlot cattle, Vet Clin North Am Food Anim Pract (17). Philadelphia, WB Saunders, pp. 189-207, 2001. 